\title{
Transmural variation and anisotropy of microvascular flow conductivity in the rat myocardium
}

\author{
Amy F. Smith ${ }^{1}$, Rebecca J. Shipley ${ }^{2}$, Jack Lee ${ }^{3}$, Gregory B. Sands ${ }^{4}$, Ian J. LeGrice ${ }^{4}$, and \\ Nicolas P. Smith ${ }^{3,5}$
}

${ }^{1}$ Oxford Centre for Collaborative Applied Mathematics, Mathematical Institute, University of Oxford, Woodstock Road, Oxford OX2 6GG, UK ²Department of Mechanical Engineering, University College London, Torrington Place, London WC1E 7JE, UK ${ }^{3}$ Department of Biomedical Engineering, King's College London, St. Thomas Hospital, London SE1 7EH, UK ${ }^{4}$ Department of Physiology, Faculty of Medical and Health Sciences, The University of Auckland, Private Bag 92019, Auckland 1142, New Zealand ${ }^{5}$ Faculty of Engineering, The University of Auckland, Private Bag 92019, Auckland 1142, New Zealand

\section{Abstract \\ Transmural variations in the relationship between structural and fluid transport properties of myocardial capillary networks are determined via continuum modelling approaches using recent three-dimensional (3D) data on the microvascular structure. Specifically, the permeability tensor, which quantifies the inverse of the blood flow resistivity of the capillary network, is computed by volume-averaging flow solutions in synthetic networks with geometrical and topological properties derived from an anatomically-detailed microvascular data set extracted from the rat myocardium. Results show that the permeability is approximately ten times higher in the principal direction of capillary alignment (the 'longitudinal' direction) than perpendicular to this direction, reflecting the strong anisotropy of the microvascular network. Additionally, a $30 \%$ increase in capillary diameter from subepicardium to subendocardium is shown to translate to a $130 \%$ transmural rise in permeability in the longitudinal capillary direction. This result supports the hypothesis that perfusion is preferentially facilitated during diastole in the subendocardial microvasculature to compensate for the severely-reduced systolic perfusion in the subendocardium.}

\section{Keywords}

Myocardial blood flow; Microvascular networks; Transmural functional differences; Homogenization; Darcy flow; Flow conductivity

Address for correspondence: Nicolas P. Smith; Faculty of Engineering, The University of Auckland, Private Bag 92019, Auckland 1142, New Zealand. Telephone: +64 9373 7599. np.smith@auckland.ac.nz. 


\section{Introduction}

During systole, myocardial contractions and high left-ventricular pressure produced by cardiac pump function induce significant compression of the subendocardial capillaries. This increased flow resistivity reduces perfusion ${ }^{8}$ which, combined with a higher metabolic demand, leads to a higher risk of ischaemia in the subendocardium than in subepicardial tissue $^{9}$. However, the exact link between transmural variations in microvascular structure and flow have not yet been resolved experimentally at the capillary scale ${ }^{31}$. In this paper, we seek to bypass these experimental limitations by exploiting theoretical techniques to predict the transmural gradient in tissue-scale flow properties directly from microvascular network geometry. This is achieved by simulating flow in synthetic networks with geometrical properties derived from 3D anatomical data extracted from the rat myocardium.

Detailed information on the 3D spatial arrangement of the coronary microvasculature has recently been obtained via ex vivo vascular casting, high-resolution imaging and automated post-processing technologies ${ }^{12 ; 17}$. However, since these methods are currently only possible for small tissue sections, many vessels (more than $10^{4}$ in the data set of Lee et al. ${ }^{17}$ ) are bisected at the sample borders. Thus meaningful blood flow simulations within these microvascular networks require prior knowledge of suitable boundary conditions (BCs). The definition of these boundary values is hindered by the limits of in vivo imaging and measurement techniques, with capillary flow measurements restricted to the endocardial surface $^{15}$ and pressures recorded only in vessels $>100 \mu \mathrm{m}$ in diameter ${ }^{4}$.

The strong influence of capillary BCs on network-scale flow properties was recently demonstrated by Lorthois et al. ${ }^{18}$, who conducted Poiseuille flow simulations in a reconstructed 3D cerebral microvascular network. Enforcing zero-flux BCs at boundary capillaries, effectively assuming the network was independent of neighboring arteriolar supply regions, minimized the total blood flow entering the network. Uniform pressure capillary BCs, chosen to satisfy zero net flux out of the capillaries and thus requiring that network outflow was balanced by inflow from neighboring regions, maximized the total inflow ( 0.33 vs. $2.36 \mathrm{~mL} \mathrm{~min}^{-1} \mathrm{~g}^{-1}$ with a discharge hematocrit of $\mathrm{HD}=0.4$ at the main arterioles). Hence the link between microvascular network geometry and effective fluid transport continues to be difficult to elucidate.

Continuum-based mathematical modelling approaches which are independent of the choice of BCs seek to address this issue. Applying this approach, Shipley and Chapman ${ }^{25}$ employed mathematical averaging techniques to derive a macroscopic Darcy flow model, which ensures computational tractability whilst capturing the key capillary-scale fluid dynamics within the microscopic network geometry. In this paper, we define permeability as the inverse of flow resistivity through the microvascular network (analogous to electrical conductivity), rather than referring to the leakage of fluid through capillary walls. Under this definition, the permeability tensor is a tissue-scale metric which links the pressure gradient and the averaged fluid velocity. The permeability tensor is calculated by volume-averaging the flow solution to a periodic boundary value problem defined on sub-units which represent the microvascular network. 
The formulation of this mathematical averaging method requires these sub-units to be spatially-periodic. Although microvascular networks in living organisms are unlikely to have a precisely self-repeating structure, we hypothesize that capillary networks in the myocardium are approximately periodic. This is justified by observations of significant spatial organization in these networks, which are composed of long, parallel ('longitudinal') capillaries connected by shorter anastomoses ${ }^{1 ; 13}$. In this study, the theoretical modelling framework developed by Shipley and Chapman ${ }^{25}$ is employed to compute a physiologicallymeaningful permeability tensor for the 3D microvascular data set of Lee et al. ${ }^{17}$. This is achieved by parameterizing synthetic networks (which are spatially periodic to comply with the modelling framework) with geometrical statistics from the discrete data.

The distinctive anisotropy of the coronary capillaries, which is hypothesized to play a key role in microvascular function within the rhythmically-contracting myocardium in vivo ${ }^{14 ; 17}$, is incorporated into this model through an anisotropic permeability tensor, which is calculated via a principal component analysis on discrete sections of the network data. The calculated principal values quantify the degree of microstructural anisotropy. Capillaries in the data set are grouped into three types (longitudinal, or in-sheet/sheet-normal crossconnecting) according to their alignment with the principal axes, and the distributions of lengths and diameters for each capillary type are used as inputs for generating the synthetic networks.

Finally, calculation of the permeability tensor for discrete sections of the data enables quantification of the degree of transmural gradient in tissue-scale flow properties as a result of anatomical variation, which is important in the context of the increased risk of ischaemia in the subendocardium. It is predicted that diastolic permeability is higher in the subendocardium than the subepicardium, which is hypothesized to compensate in part for the strong reduction in subendocardial perfusion during systole as a result of increased microvascular resistance produced by compression of the embedded coronary vasculature during cardiac contraction.

\section{Materials and methods}

\subsection{Structural properties of the coronary capillaries}

The methods presented in this study, summarized in Figure 1, were implemented in MATLAB R2013a and applied to the rat microvascular data set, which was obtained ex vivo by perfusing the adenosine-dilated vasculature of the rat myocardium with a corrosion casting mixture at a perfusion pressure of $80 \mathrm{mmHg}$. Confocal laser scanning microscopy, high-precision sectioning and automated image processing techniques were employed by Lee et al. ${ }^{17}$ to digitally reconstruct $\mathrm{a} \approx 2 \mathrm{~mm}^{3}$ section of the vasculature at sub-micron resolution (see Figure 2). In this data set, the $x, y$ and $z$-axes correspond to the circumferential, transmural (endocardium to epicardium) and apex-base directions. The region below $y=600 \mu \mathrm{m}$ was neglected because of large regions absent of vessels, likely due to the uneven surface typical of the endocardium.

Since a gold-standard reference data set for the radius-detection algorithm was unavailable and the extracted diameters were found to be significantly larger than those reported 
previously in the rat ${ }^{21 ; 22 ; 29}$, the approach of Secomb et al. ${ }^{24}$ was applied to the network data. Specifically, a scaling factor was applied to all diameters to match the mean of diameters reported for the rat myocardium $(5.1 \mu \mathrm{m})^{21 ; 22 ; 29}$, obtaining a standard deviation (S.D.) of $2.1 \mu \mathrm{m}$. After this scaling, the capillary volume fraction was $5.7 \%$, similar to measurements in the dog myocardium ${ }^{19}$.

Firstly, the main arterioles and venules were excluded from subsequent analysis by employing a geometry-based vessel classification method (see $S{ }^{2} h^{26}$ ). In brief, this algorithm distinguishes branching trees from an interconnected capillary mesh by stepping through the network in a sequence that depends on both branching order and vessel diameter, and then identifying loops within the network. A principal component analysis (PCA) weighted by vessel length was performed on the remaining capillaries to quantify the anisotropy in capillary orientation and identify the axes best describing this alignment ${ }^{5}$. The Cartesian components of the covariance matrix were computed for the set of vectors from the start node to the end node of each capillary segment (unbranched section of capillary). The normalized eigenvalues of this covariance matrix, sorted in order of descending magnitude, are the principal values $\left\{\lambda_{1}, \lambda_{2}, \lambda_{3}\right\}$ which indicate the proportion of the variance in capillary orientation accounted for by each axis. The corresponding eigenvectors of the covariance matrix are the principal axes $\left\{\mathbf{e}_{1}, \mathbf{e}_{2}, \mathbf{e}_{3}\right\}$, giving the principal directions of capillary alignment. To capture the gradually-varying capillary alignment, the data was discretized into 5 sections transmurally, 5 sections in the circumferential direction and 2 sections in the apex-base direction, to yield sub-blocks of dimension $363 \times 329 \times 336 \mu \mathrm{m}^{3}$. The principal axes and corresponding principal values were computed for the capillaries within each section.

Capillaries were grouped into three types according to their spherical polar angles $(\phi, \theta)$ with respect to the local principal axes (see Figure 3 ). The regions occupied by each capillary type were specified by critical angles $\phi_{\mathrm{c}}$ and $\theta_{\mathrm{c}}$ : longitudinal capillaries (CL) satisfied $|\theta| \leq \theta_{c}$ and $|\phi| \leq \phi_{c}$; cross-connecting capillaries were sub-categorized into in-sheet (CS) capillaries $\left(|\theta| \leq \theta_{\mathrm{c}}\right.$ and $\left.|\phi|>\phi_{\mathrm{c}}\right)$ or sheet-normal $(\mathrm{CN})$ capillaries $\left(|\theta|>\theta_{\mathrm{c}}\right)$. The mean and S.D. of lengths and diameters for each capillary type were recorded, and the sensitivity of these metrics to $\phi_{\mathrm{c}}$ and $\theta_{\mathrm{c}}$ was investigated.

\subsection{Calculation of the permeability tensor}

Mathematical averaging ('homogenization') techniques were employed to predict tissuescale flow properties following the approach of Shipley and Chapman ${ }^{25}$, who derived equations for effective fluid and drug transport in vascular networks. In the current study it was assumed that vessels were healthy i.e. non-leaky, so that there was no interstitial flow, and a no-slip, no-flux boundary condition was applied for the blood velocity at capillary walls. Assuming well-separated capillary (micro) and tissue (macro) length-scales and starting with viscous-dominated Stokes flow at the capillary scale, an asymptotic expansion was performed for the blood velocity and pressure in terms of the ratio of length scales. In brief, it was deduced that the flow solution was given by a linear superposition of contributions proportional to the tissue-scale pressure gradient in each of the principal directions $\mathbf{e}_{j}$. The weightings of these contributions were calculated by solving a periodic 
boundary value problem in terms of the capillary-scale variations in pressure, $P^{j}$, and velocity, $\mathbf{w}^{j}$, defined on periodic sub-units ('micro-cells') of the capillary network.

An analytical solution to this micro-cell problem was found by assuming that capillary diameters were typically much less than the length of the micro-cell (lubrication scalings) and by assuming that the flow in each capillary was radially-symmetric. In $2 \mathrm{D}$ (which is justified later) this led to the following expression for the micro-cell flux $\mathbf{q}_{m}^{j}$, defined as $\mathbf{w}^{j}$ integrated over the cross-section of capillary $m$ :

$$
\mathbf{q}_{m}^{j}=\frac{\pi D_{m}^{4}}{128 \mu_{m}}\left(\frac{\Delta P_{m}^{j}}{L_{m}}+\mathbf{e}_{j} \cdot \mathbf{e}_{m}\right) \mathbf{e}_{m} \mu \mathrm{m}^{5} \mathrm{~s} \mathrm{~kg}^{-1}, j=1,2,
$$

where $D_{m}, L_{m}$, and $\mu_{m}$ are the diameter, length and viscosity respectively, $\Delta P_{m}^{j}$ is the drop in micro-cell pressure $P^{j}$ along the vessel length, and $\mathbf{e}_{m}$ is the unit vector directed down the center-line of capillary $m$. This is a modified Poiseuille law, with an extra forcing term $\mathbf{e}_{j}$. $\mathbf{e}_{m}$ due to the tissue-scale pressure gradient. To account for the non-Newtonian rheology at this scale, the in vivo viscosity law of Pries and Secomb ${ }^{23}$ was used with a constant discharge hematocrit of $\mathrm{H}_{\mathrm{D}}=0.45$ to give $\mu_{m}$ as a function of $D_{m}$. Conservation of microcell flux at nodes and periodicity of micro-cell flux and pressure at boundary nodes were enforced. To obtain a unique solution, the volume average of the micro-cell pressure was defined to be zero. Together these conditions led to two (for $j=1,2$ ) linear systems of equations in terms of the micro-cell pressure $P^{j}$ at each node, which was solved using standard linear solvers.

The permeability tensor $\mathbf{K}$, defined as the volume-average of micro-cell velocity $\mathbf{w}^{j}$, transmits capillary-scale flow properties within specific micro-cell networks to the tissuescale fluid transport equation (Darcy's Law):

$$
\mathbf{u}=-\mathbf{K} \cdot \nabla p
$$

where $\mathbf{u}$ is the volume-averaged tissue-scale blood velocity and $\nabla p$ is the tissue-scale pressure gradient (note that $\mathbf{u}$ and $\nabla p$ are not calculated in this paper). The permeability tensor $\mathbf{K}=\left[\mathbf{K}^{1} \mathbf{K}^{2}\right]$ was calculated via:

$$
\mathbf{K}^{j}=\left[\begin{array}{c}
\mathrm{K}_{1 j} \\
\mathrm{~K}_{2 j}
\end{array}\right]=\frac{1}{|\Omega|} \sum_{m=1}^{M} \mathbf{q}_{m}^{j} L_{m}
$$

where $|\Omega|$ is the micro-cell domain volume, $M$ is the total number of vessel segments, and $\mathbf{q}_{m}^{j}$ is obtained in terms of the micro-cell pressure solution $P^{j}$ via Equation (1). The permeability components $K_{1 j}$ and $K_{2 j}$ represent the volume-averaged flow in the $\mathbf{e}_{1}$ and $\mathbf{e}_{2}$ directions respectively due to a forcing in the $\mathbf{e}_{j}$-direction.

\subsection{Construction of synthetic networks}

To parameterize physiologically-based micro-cells which are constrained to be spatially periodic as required by the homogenization framework, the inbuilt structural organization of the coronary capillaries was exploited. Specifically, synthetic spatially-periodic micro-cell 
networks were constructed by sampling from the morphological data (lengths and diameters) collected from the three capillary types. Within these abstracted networks only longitudinal $\left(C_{L}\right)$ and in-sheet cross-connecting $\left(C_{S}\right)$ capillaries were incorporated into the micro-cell networks, since a large proportion (quantified in the results section) of capillaries lay within a smoothly-varying two-dimensional manifold following the sheet architecture of cardiac muscle ${ }^{16}$, with longitudinal capillaries preferentially oriented in the direction of the muscle fibers ${ }^{17}$. Thus the synthetic networks were constructed to be two-dimensional (2D) with coordinates $0<X<X_{\max }$ and $0<Y<Y_{\max }$, embedded in a 3D domain with thickness given by the mean length of $C_{N}$ capillaries (see Figure 4).

Each individual segment was assumed to be cylindrical with constant diameter along its length ${ }^{19}$. Longitudinal capillaries running the entire length of the micro-cell, parallel to the $X$-axis (referred to as 'elements') were linked by perpendicular $C_{S}$ segments. The placement of longitudinal elements was determined, followed by the location of $C_{S}$ linking neighboring elements. Each section of longitudinal element between successive nodes (segment junctions) was defined to be a $C_{L}$ segment. A typical micro-cell network is shown in Figure 4.

The separation of longitudinal elements is equivalent to the length of $C_{S}$ linking element $i$ to element $i+1$, and determined by sampling from a log-normal distribution with mean and S.D. given by $C_{S}$ lengths extracted from the data set (see Algorithm 1 in Supplementary Material). Starting at $Y=0$, this procedure was repeated to find the $Y$-coordinate $Y_{i}$ of element $i$ until the height of the micro-cell $Y_{\max }$ was reached, at which stage a final element was placed at $Y_{n}=Y_{\max }$.

Following this step, the exact placement of cross-connections $C_{S}$ were determined (see Algorithm 2 in Supplementary Material). Starting at $X_{0}=0$ on element 1 , the $X$-coordinate of the $j^{\text {th }} C_{S}, X_{j}$, was given by $X_{j-1}$ plus sampled length $H_{j}$ taken from a log-normal distribution with mean $m$ and standard deviation $s$, so that this segment has start node at $\left(X_{j}, Y_{1}\right)$ and end node at $\left(X_{j}, Y_{2}\right)$. This was repeated until $X=X_{\max }$ was reached, with the same procedure then iterated for $C_{S}$ starting on the elements at $Y=Y_{2}, Y=Y_{3}$, etc. until the element at $Y=Y_{n}$ was reached. The periodicity assumption requires that boundary segments align at opposite sides of the micro-cell: $C_{L}$ segments running in parallel across the length of the micro-cell automatically satisfy this condition; however $C_{S}$ segments starting on the final element at $Y=Y_{n}$ must connect to the first element at $Y=Y_{l}$ (shown in yellow in Figure 4). To avoid the placement of $C_{S}$ segments unrealistically close to each other a minimum separation of $1.41 \mu \mathrm{m}$ (the minimum segment length in the data set) between nodes was enforced.

A connectivity matrix was created recording the start and end nodes of each segment (defining the direction of positive flow in subsequent simulations). The sampled lengths $H_{j}$ do not translate exactly to the mean and S.D. of $C_{L}$ segment lengths, because nodes on element $i$ mark the junction with $C_{S}$ linking to elements $(i-1)$ and also $(i+1)$. For this reason, $H_{j}$ were sampled from a log-normal distribution with mean $m=2 \times 37.7 \mu \mathrm{m}$ and S.D. $s=$ $2 \times 28.8 \mu \mathrm{m}$. The network periodicity was accounted for when recording boundary segment lengths: on each element the $C_{L}$ boundary segments (shown in red in Figure 4) are recorded 
as one segment, and similarly for the $C_{S}$ boundary segments (shown in yellow). Diameters were assigned to each $C_{L}$ and $C_{S}$ segment by sampling from a log-normal distribution using the corresponding mean and S.D. for each capillary type. The micro-cell problem was then solved (as detailed in Appendix A) on 1000 synthetically-generated networks. The sensitivity of the permeability tensor $\mathbf{K}$ to micro-cell length $X_{\max }$ and height $Y_{\max }$ and to the input geometrical properties of the micro-cell networks was quantified in order to highlight the important parameters in determining tissue-scale flow properties.

\subsection{Transmural functional variations}

Transmural variations in permeability $\mathbf{K}$ were computed by constructing 1000 micro-cell networks using geometrical data collected over discrete $x$ and $z$ sections in terms of the $y$ coordinate of the mid-point of each discrete slice (corresponding to the transmural distance).

\section{Results}

\subsection{Results of PCA}

The discretized principal axes $\mathbf{e}_{1}$ and $\mathbf{e}_{2}$ exhibited a smooth variation across the microvascular block (see Figure 5). The first principal axis $\mathbf{e}_{\mathbf{1}}$ was oriented roughly parallel to the epicardial surface, angled towards the apex at the endocardium and twisting to point more towards the base near the epicardium. Meanwhile the $\mathbf{e}_{\mathbf{2}}$ direction pointed generally towards the apex but, moving from endocardium to epicardium, twisted from pointing towards the endocardium to lying approximately parallel to the epicardial surface. The principal values (mean \pm S.D) were $\lambda_{1}=0.74 \pm 0.05, \lambda_{2}=0.18 \pm 0.04$ and $\lambda_{3}=0.08 \pm 0.02$. The distribution of angles $\phi$ and $\theta$ for capillaries in one discrete section of the block is shown in Figure 6. Using critical threshold angles $\phi_{c}=45^{\circ}$ and $\theta_{c}=41.8^{\circ}$ to ensure that each region used to group capillaries had equal volume in parameter space, the resulting geometrical statistics for each capillary type collected over the whole block are summarized in Table 1. These statistics were not significantly sensitive to changes in critical angles $\phi_{c}$ and $\theta_{\mathrm{c}}$ and there was no clear cut-off between vessel types: a 30\% increase in $\phi_{\mathrm{c}}$ led to less than $1 \%$ change in the mean diameters of $C_{L}$ and $C_{S}$ segments, while the mean $C_{N}$ length increased by $6.1 \%$ in response to a $30 \%$ decrease in $\theta_{c}$. The assumption of a $2 \mathrm{D}$ micro-cell composed of $C_{L}$ and $C_{S}$ only is supported by the data: $91.5 \%$ of capillaries were oriented within $41.8^{\circ}$ of $\mathbf{e}_{1}-\mathbf{e}_{2}$ plane. The distribution of diameters was similar for all capillary types, while the mean length of the longitudinal $\left(C_{L}\right)$ segments $(38.0 \mu \mathrm{m})$ was $53 \%$ longer than that of the $C_{S}$ segments (and 76\% longer than the mean $C_{N}$ length). The distributions of lengths and diameters for all capillary types were approximately log-normal. The mean and S.D. in lengths and diameters of $C_{L}$ and $C_{S}$ capillaries were used as inputs into the micro-cell network construction procedure, and the micro-cell domain thickness was prescribed by the mean length of $C_{N}$ segments $(21.6 \mu \mathrm{m})$.

\subsection{Permeability of synthetic networks}

Appropriate micro-cell length $X_{\max }$ and height $Y_{\max }$ were determined by computing the permeability of 1000 stochastically-generated networks for a range of micro-cell sizes. A large micro-cell size would challenge the assumption of length-scale separation, while a small micro-cell size increases the sensitivity of the extracted permeability values to the 
stochastically-generated network structure. The mean of the $K_{11}$ permeability component was more sensitive to micro-cell length than height, and increased sharply for micro-cell lengths $<200 \mu \mathrm{m}$ (see Figure 7). A micro-cell of size $450 \times 300 \times 21.6 \mu \mathrm{m}^{3}$ or greater was needed to obtain mean $K_{11}$ and $K_{22}$ values within $10 \%$ of the mean values obtained with a $1000 \times 1000 \times 21.6 \mu \mathrm{m}^{3}$ micro-cell. Subsequent simulations were performed on a micro-cell of size $500 \times 300 \times 21.6 \mu \mathrm{m}^{3}$, for which $K_{11}=(3.3 \pm 0.8) \times 10^{-3} \mathrm{~mm}^{3} \mathrm{~s} \mathrm{~kg}^{-1}$ and $K_{22}=(3.1 \pm 1.0)$ $\times 10^{-4} \mathrm{~mm}^{3} \mathrm{~s} \mathrm{~kg}^{-1}$ ( $K_{11}$ was $10.8 \times K_{22}$ on average), reflecting the anisotropic structure of the underlying network. The off-diagonal permeability components $K_{12}$ and $K_{21}$ were equal and close to zero $\left((0.0013 \pm 9.0) \times 10^{-5} \mathrm{~mm}^{3} \mathrm{~s} \mathrm{~kg}^{-1}\right)$.

Due to the constraints imposed during the construction process, the distribution of segment lengths in the stochastically-generated synthetic networks did not exactly match those of the original data set (see Table 2). The mean length of $C_{L}$ segments in the micro-cell networks was $5.4 \%$ higher than in the data set (with a 5.9\% higher S.D.), while the mean $C_{S}$ length was $4.8 \%$ lower than in the data set (with $4.7 \%$ lower S.D.). These length errors are predicted to lead to a $6.4 \%$ overestimate in the mean $K_{11}(6.3 \%$ overestimate in the S.D. of $\left.K_{11}\right)$ combined with a $10.0 \%$ underestimate in the mean of $K_{22}(11.0 \%$ underestimate in S.D.).

The permeability tensor was highly sensitive to changes in segment diameters: see Table 3 . A $10 \%$ increase in the mean $C_{L}$ diameter led to $54.3 \%$ increase in mean $K_{11}$ (combined with $43.9 \%$ increase in S.D.) and $26.6 \%$ increase in mean $K_{22}$ (21.3\% increase in S.D.). This strong effect on $K_{22}$ occurs because flow forced in the $\mathbf{e}_{2}$ direction (i.e. when $j=2$ in Equation (1)) is diverted along $C_{L}$ as well as $C_{S}$ due to the off-set cross-connections, and is thus strongly affected by diameters of both capillary types. A $10 \%$ rise in the mean $C_{S}$ diameter had a similar effect on $K_{22}$ (21.9\% increase in the mean and $23.8 \%$ increase in S.D.), while less than $10 \%$ change was found for the mean or S.D. in $K_{11}$. Changing the S.D. of $C_{L}$ or $C_{S}$ diameters by $10 \%$ led to less than $10 \%$ change in either the mean or S.D. of $K_{11}$ and $K_{22}$, demonstrating that the variance in diameters was much less important than the mean. Increasing the input mean horizontal length $(m)$ by $10 \%$ resulted in an $11.7 \%$ decrease in $K_{22}$ (see Table 4), while a $10 \%$ rise in the mean $C_{S}$ length led to an $8.7 \%$ drop in the mean $K_{11}$.

Across all results the permeability was consistently much less sensitive to changes in segment length than to changes in the mean diameter. This is to be expected since the permeability is proportional to the fourth power of diameters, but inversely proportional to capillary length (see Equation 1). This relationship combined with the effect of a nonNewtonian viscosity directly explains the impact of $C_{L}$ diameter changes to the mean $K_{11}$; however, $K_{22}$ was affected by diameters of both $C_{L}$ and $C_{S}$ segments whilst also experiencing a more subtle dependence on the anisotropic network topology.

\subsection{Transmural variations}

The principal values did not exhibit a correlation with transmural distance, indicating that the level of structural anisotropy does not vary from the subendocardium (ENDO) to the subepicardium (EPI). The capillary density (number of capillaries per $\mathrm{mm}^{3}$ ) was $100.2 \%$ higher in ENDO than EPI on average over all capillary types, though most significantly the 
density of capillaries was $131.5 \%$ higher in the mid-myocardium in comparison to the EPI (see Figure 8a). Figure 8b) shows the significant increase in mean diameter from EPI to ENDO (a 30.1\% rise averaged over the three capillary types), confirming the findings of May-Newman et al. ${ }^{19}$. Mean $C_{L}$ lengths increased slightly with transmural depth (a $10.6 \%$ rise from $36.2 \mu \mathrm{m}$ to $40.0 \mu \mathrm{m}$ ); the length of $C_{S}$ segments was slightly lower in the midmyocardium $(24.2 \mu \mathrm{m})$ than peripheral regions $\left(26.1 \mu \mathrm{m}\right.$ in the EPI); the mean $C_{N}$ length increased 33.3\% from EPI to ENDO. Using these results as inputs to the micro-cell networks revealed the strong dependence of the permeability on transmural location (see Figure 8c). The mean of $K_{11}$ increased $130 \%$ from EPI $\left(2.0 \times 10^{-3} \mathrm{~mm}^{3} \mathrm{~s} \mathrm{~kg}^{-1}\right)$ to ENDO $\left(4.6 \times 10^{-3} \mathrm{~mm}^{3} \mathrm{~s} \mathrm{~kg}^{-1}\right)$; similarly, the mean of $K_{22}$ ranged from $2.3 \times 10^{-4} \mathrm{~mm}^{3} \mathrm{~s} \mathrm{~kg}^{-1}$ up to $4.9 \times 10^{-4} \mathrm{~mm}^{3} \mathrm{~s} \mathrm{~kg}^{-1}$ (an increase of $117 \%$ ).

\section{Discussion}

The principal component analysis conducted in this paper confirmed that the 3D structure of the coronary capillary network is highly anisotropic. Data extracted from this analysis was used to compute the network permeability tensor via flow solutions in microvascular subunits ('micro-cells'). In this way the link between this structural anisotropy and tissue-scale fluid transport properties was quantified, showing that the permeability in the direction of longitudinal capillaries was $10.8 \times$ larger than in the direction of cross-connecting capillaries. The distribution of capillary diameters was a crucial determinant of tissue-scale perfusion, with changes to the mean diameter of longitudinal segments having the strongest effect on the permeability tensor.

Previously, Wieringa et al. ${ }^{34}$, Beard and Bassingthwaighte ${ }^{2}$, and Goldman and Popel ${ }^{7}$ studied similar spatially-periodic synthetic networks composed of long, parallel capillaries with cross-connections; however, capillaries were assigned uniform diameters. The synthetic networks developed here had large S.D. in capillary diameters, and although a $10 \%$ change to the diameter S.D. had little effect, if the S.D. of diameters were set to zero (i.e. imposing uniform diameters in $C_{L}$ and $C_{S}$ segments), the mean $K_{11}$ and $K_{22}$ would be $60.6 \%$ and $95.8 \%$ higher respectively. Non-zero diameter variance reduces the permeability due to local pressure gradients which force flow to deviate along the cross-connections rather than following the shortest path across the micro-cell, hence increasing the total network resistance. Note that an approximate estimate of $\mathbf{K}$ can be obtained via a simple calculation using the capillary density and mean capillary diameter and length, which predicts similar values but with a larger transmural range $\left(K_{11}=(0.9-6.1) \times 10^{-3} \mathrm{~mm}^{3} \mathrm{~s} \mathrm{~kg}^{-1}, K_{22}=(2.9-\right.$ 16.2) $\times 10^{-4} \mathrm{~mm}^{3} \mathrm{~s} \mathrm{~kg}^{-1}$ ) most likely because this does not account for the non-zero diameter S.D. which is a feature of the micro-cell networks.

One limitation to this model is that a persistence in diameters between neighboring $C_{L}$ capillaries in the data set was not replicated in the micro-cell networks. The ratio of diameters at bifurcations was $1.05 \pm 0.36$ in the data, compared with $1.14 \pm 0.63$ in the micro-cells. To investigate the effect of this error, new micro-cells were generated with the first $C_{L}$ segment diameter on each longitudinal element was sampled as before, but subsequent $C_{L}$ segment diameters were a specified ratio (sampled from a distribution obtained from the data) of the previous neighboring segment's diameter. Output $C_{L}$ 
diameters were $5.0 \pm 3.0 \mu \mathrm{m}$ (with S.D. significantly higher than 1.9 expected from the data), while $K_{11}$ was $(4.46 \pm 1.73) \times 10^{-3} \mathrm{~mm}^{3} \mathrm{~s} \mathrm{~kg}^{-1}$. For comparison, micro-cells were generated without diameter correlation but with $C_{L}$ diameters sampled from the distribution obtained above, yielding a larger diameter ratio of $1.41 \pm 1.41$ and $K_{11}=(2.41 \pm 0.73)$ $\times 10^{-3} \mathrm{~mm}^{3} \mathrm{~s} \mathrm{~kg}^{-1}$. The mean $K_{11}$ was $54.0 \%$ of the value obtained with diameter correlation, indicating that by neglecting diameter correlation in the micro-cell networks we may have been underestimating $K_{11}$ (although this difference may be exaggerated by the high diameter S.D.). However, incorporating this feature in a manner which is also consistent with the expected S.D. of diameters appears far from straightforward but would be an interesting and potentially important extension to this work.

The simple, 2D micro-cell construct assumed in this paper with cross-connections at $90^{\circ}$ to the longitudinal elements agrees with the ' $\mathrm{H}$ '-type of branching, which was the most common capillary branching type observed by Kassab and Fung ${ }^{13}$. A clear extension to the model which is beyond the scope of this paper would be to construct 3D micro-cell networks including $C_{N}$ segments. Since $C_{N}$ had similar geometrical properties to $C_{S}$ but approximately one third the capillary density, it is predicted that the permeability in the sheet-normal direction $\left(K_{33}\right)$ could be approximately $10^{-4} \mathrm{~mm}^{3} \mathrm{~s} \mathrm{~kg}^{-1}$, which while small could contribute to tissue-scale flow if there were a large pressure gradient in this direction.

Due to experimental limitations, there is very little quantitative information about tissuelevel pressure gradients within the myocardium in any of the coordinate directions. A nonnegligible transmural pressure difference (corresponding roughly to the sheet-normal direction) in vessels of diameter $>100 \mu \mathrm{m}$ was reported by $\mathrm{Chilian}^{4}$, though this may be due in part to the spatial location of terminal arterioles supplying the capillary network. A key advantage of the approach presented here is that $\mathbf{K}$ is de-coupled from tissue-scale pressure gradients (which are implicit in coarse-scale experimental measurements of myocardial blood perfusion) and so could be used in poroelastic models to describe the potential flow capacity of the capillary network.

In this study, variations in the geometrical properties of the capillary network were related to transmural functional differences. The mean capillary diameter was $\approx 30 \%$ larger in the subendocardium than the subepicardium, contributing to a significant transmural increase in the computed permeability ( $\approx 130 \%$ in the longitudinal direction). The method presented here provides a novel technique for combining sophisticated modelling techniques with microstructural statistics to predict flow properties from anatomical data. The permeability tensor in itself provides fundamental information about (the inverse of) network flow resistivity. In addition, these permeability results could be used to parameterize tissue-scale models of volume-averaged flow in the myocardium ${ }^{3 ; 10 ; 11 ; 27 .}$

Since the data used in this paper was obtained ex vivo with relaxed cardiac muscle and fully-dilated vessels, the reconstructed vasculature is most representative of the diastolic phase of the cardiac cycle. The results of this study support the hypothesis that subendocardial network permeability is significantly higher than subepicardial permeability during diastole, most likely in order to compensate (to some extent) for the reduced systolic perfusion, and the associated higher risk of ischaemia, in the subendocardium ${ }^{30}$. The 
permeability was shown here to be strongly dependent on capillary diameters, and so would be expected to reduce significantly in the subendocardium in response to increased microvascular constriction as a result of systolic myocardial contraction. The methods developed in this paper could be used in future to quantify the microvascular contribution to systolic flow impediment in the context of active myocardial contraction ${ }^{27}$.

Although capillaries cannot actively dilate or constrict, flow across the capillary network in the living myocardium depends strongly on driving pressures of upstream terminal arterioles, which respond to vasoregulatory signals. However in microvascular disease, coronary flow reserve is impaired and arterioles are almost fully dilated at rest ${ }^{20}$. In this context, $\mathbf{K}$ represents an important metric of passive flow conductivity once the vasoactive response is exhausted. This framework provides a tool which could in future be used to quantify the effects of structural changes induced by microvascular diseases such as diabete ${ }^{27}$, which are important for understanding whole-organ coronary flow in the clinic.

These permeability calculations can be validated using experimental quantifications of myocardial blood flow (MBF). The perfusion $\left(\mu \mathrm{m}^{3} \mathrm{~s}^{-1}\right)$ into a given region of the myocardium is obtained by integrating the Darcy velocity over a cross-sectional area $A$ $\left(\mu \mathrm{m}^{2}\right)$ :

$$
\text { Perfusion }=-\int_{A}(\boldsymbol{K} \cdot \nabla p) \cdot \mathbf{n} \mathrm{d} A,
$$

where $\mathbf{n}$ is the unit vector normal to $A$. If $\mathbf{n}$ is parallel to the principal axis $\mathrm{e}_{1}$ and the pressure gradient is given by a uniform pressure drop ${ }^{4}$ of $\Delta p=15 \mathrm{mmHg}$ over an arteriolarvenular path length ${ }^{28}$ of $l=310 \mu \mathrm{m}$, then

$$
\text { Perfusion }=K_{11} \times \frac{\Delta p}{l} \times 0.133 \times 10^{-3} \times A, \quad(5
$$

where the factor $0.133 \times 10^{-3}$ converts from $\mathrm{mmHg}$ to $\mathrm{kg} \mathrm{m}^{-1} \mathrm{~s}^{-2}$, and $K_{11}$ is in $\mu \mathrm{m}^{3} \mathrm{~s} \mathrm{~kg}^{-1}$. Alternatively,

$$
\text { Perfusion }=\frac{\mathrm{MBF}}{60} \times \rho \times A \times l, \quad(6)
$$

where the factor of 60 converts from min to s, and $\rho=1.053 \mathrm{~g} \mathrm{~mL}^{-1}$ is the myocardial density $^{32}$. Substituting Equation (6) into (5) yielded an estimated MBF in the range 2.4-5.5 $\mathrm{mL} \min ^{-1} \mathrm{~g}^{-1}$ depending on transmural depth. Using magnetic resonance imaging via a spin-labelling technique, Waller et al. ${ }^{33}$ measured a MBF of $3.5 \mathrm{~mL} \mathrm{~min}^{-1} \mathrm{~g}^{-1}$ in the rat, which is within this predicted range.

This study has revealed the transmural variation in the orientation of the myocardial capillary network, which can be characterized by capillaries aligned with the longitudinal, sheet or sheet-normal directions. Combining mathematical averaging techniques with detailed anatomical data enabled the extraction of a permeability tensor, which is a physiologically relevant metric for characterizing myocardial perfusion. This permeability 
tensor was shown to be highly sensitive to capillary diameters, which exhibit a strong dependence on transmural location. Future research will involve comparing a continuumbased Darcy flow model parameterized by these permeability values to a flow solution within the discrete vascular network estimated via the optimization procedure of Fry et al. ${ }^{6}$, which constrains capillary shear stress and pressure to within a physiological range.

\section{Supplementary Material}

Refer to Web version on PubMed Central for supplementary material.

\section{Acknowledgments}

The authors acknowledge support from the Virtual Physiological Rat Project (NIH1 P50 GM094503-1), the EPSRC (Engineering and Physical Sciences Research Council) under grant numbers EP/F043929/1 and EP/G007527/2, and Award No. KUK-C1-013-04 made by King Abdullah University of Science and Technology (KAUST). The authors would also like to thank Prof. Timothy W. Secomb (University of Arizona) for helpful scientific discussions.

\section{References}

1. Bassingthwaighte JB, Yipintsoi T, Harvey RB. Microvasculature of the dog left ventricular myocardium. Microvasc Res. 1974; 7:229-249. [PubMed: 4596001]

2. Beard DA, Bassingthwaighte JB. Advection and diffusion of substances in biological tissues with complex vascular networks. Ann Biomed Eng. 2000; 28:253-268. [PubMed: 10784090]

3. Chapelle D, Gerbeau J-F, Sainte-Marie J, Vignon-Clementel IE. A poroelastic model valid in large strains with applications to perfusion in cardiac modeling. Comput Mech. 2010; 46:91-101.

4. Chilian WM, Layne SM, Klausner EC, Eastham CL, Marcus ML. Redistribution of coronary microvascular resistance produced by dipyridamole. Am J Physiol Heart Circ Physiol. 1989; 256:H383-H390.

5. Cookson AN, Lee J, Michler C, Chabiniok R, Hyde E, Nordsletten DA, Sinclair M, Siebes M, Smith NP. A novel porous mechanical framework for modelling the interaction between coronary perfusion and myocardial mechanics. J Biomech. 2012; 45:850-855. [PubMed: 22154392]

6. Fry BC, Lee J, Smith NP, Secomb TW. Estimation of blood flow rates in large microvascular networks. Microcirculation. 2012; 19:530-538. [PubMed: 22506980]

7. Goldman D, Popel AS. A computational study of the effect of capillary network anastomoses and tortuosity on oxygen transport. J Theor Biol. 2000; 206:181-194. [PubMed: 10966756]

8. Goto M, Flynn AE, Doucette JW, Jansen CM, Stork MM, Coggins DL, Muehrcke DD, Husseini WK, Hoffman JI. Cardiac contraction affects deep myocardial vessels predominantly. Am J Physiol Heart Circ Physiol. 1991; 261:H1417-H1429.

9. Hoffman JIE. Transmural myocardial perfusion. Prog Cardiovasc Dis. 1987; 29:429-464. [PubMed: 2953043]

10. Hyde ER, Chabiniok R, Nordsletten DA, Smith NP. Parameterisation of multiscale continuum perfusion models from discrete vascular networks. Med Biol Eng Comput. 2013; 51:557-70. [PubMed: 23345008]

11. Hyde ER, Cookson AN, Lee J, Michler C, Goyal A, Sochi T, Chabiniok R, Sinclair M, Nordsletten D, Spaan J, van den Wijngaard JP, Siebes M, Smith NP. Multiscale parameterisation of a myocardial perfusion model using whole-organ arterial networks. Ann Biomed Eng. 2014; 42:797-811. [PubMed: 24297493]

12. Kaneko N, Matsuda R, Toda M, Shimamoto K. Three-dimensional reconstruction of the human capillary network and the intramyocardial micronecrosis. Am J Physiol Heart Circ Physiol. 2011; 300:H754-H761. [PubMed: 21148764]

13. Kassab GS, Fung YCB. Topology and dimensions of pig coronary capillary network. Am J Physiol Heart Circ Physiol. 1994; 267:H319-H325. 
14. Kassab GS, Le KN, Fung YCB. A hemodynamic analysis of coronary capillary blood flow based on anatomic and distensibility data. Am J Physiol Heart Circ Physiol. 1999; 277:H2158-H2166.

15. Kiyooka T, Hiramatsu O, Shigeto F, Nakamoto H, Tachibana H, Yada T, Ogasawara Y, Kajiya M, Morimoto T, Morizane Y, Mohri S, Shimizu J, Ohe T, Kajiya F. Direct observation of epicardial coronary capillary hemodynamics during reactive hyperemia and during adenosine administration by intravital video microscopy. Am J Physiol Heart Circ Physiol. 2005; 288:1437-1443.

16. Le Grice IJ, Smaill BH, Chai LZ, Edgar SG, Gavin JB, Hunter PJ. Laminar structure of the heart: Ventricular myocyte arrangement and connective tissue architecture in the dog. Am J Physiol Heart Circ Physiol. 1995; 269:H571-H582.

17. Lee J, Niederer S, Nordsletten D, Le Grice I, Smaill B, Kay D, Smith N. Coupling contraction, excitation, ventricular and coronary blood flow across scale and physics in the heart. Phil Trans R Soc A. 2009; 367:2311-2331. [PubMed: 19414457]

18. Lorthois S, Cassot F, Lauwers F. Simulation study of brain blood flow regulation by intra-cortical arterioles in an anatomically accurate large human vascular network: Part I: Methodology and baseline flow. NeuroImage. 2011; 54:1031-1042. [PubMed: 20869450]

19. May-Newman K, Mathieu-Costello O, Omens JH, Klumb K, McCulloch AD. Transmural distribution of capillary morphology as a function of coronary perfusion pressure in the resting canine heart. Microvasc Res. 1995; 50:381-396. [PubMed: 8583952]

20. McDonagh P, Hokama JY. Microvascular perfusion and transport in the diabetic heart. Microcirculation. 2000; 7:163-181. [PubMed: 10901496]

21. Poole DC, Batra S, Mathieu-Costello O, Rakusan K. Capillary geometrical changes with fiber shortening in rat myocardium. Circulation Research. 1992; 70:697-706. [PubMed: 1551196]

22. Potter R, Groom A. Capillary diameter and geometry in cardiac and skeletal muscle studied by means of corrosion casts. Microvasc Res. 1983; 25:68-84. [PubMed: 6835100]

23. Pries AR, Secomb TW. Microvascular blood viscosity in vivo and the endothelial surface layer. Am J Physiol Heart Circ Physiol. 2005; 289:H2657-H2664. [PubMed: 16040719]

24. Secomb T, Hsu R, Beamer N, Coull B. Theoretical simulation of oxygen transport to brain by networks of microvessels: Effects of oxygen supply and demand on tissue hypoxia. Microcirculation. 2000; 7:237-247. [PubMed: 10963629]

25. Shipley RJ, Chapman SJ. Multiscale modelling of fluid and drug transport in vascular tumours. Bull Math Bio. 2010; 72:1464-1491. [PubMed: 20099043]

26. Smith, AF. DPhil Thesis. University of Oxford; 2013. Multi-scale modelling of blood flow in the coronary microcirculation.

27. Smith NP, Kassab GS. Analysis of coronary blood flow interaction with myocardial mechanics based on anatomical models. Phil Trans R Soc A. 2001; 359:1251-1262.

28. Toborg M. The microcirculatory bed in the myocardium of the rat and the cat. Z Zellforsch. 1972; 123:369-394. [PubMed: 5008776]

29. Tomanek RJ, Searls JC, Lachenbruch PA. Quantitative changes in the capillary bed during developing, peak, and stabilized cardiac hypertrophy in the spontaneously hypertensive rat. Circ Res. 1982; 51:295-304. [PubMed: 6214331]

30. van de Hoef TP, Nolte F, Rolandi MC, Piek JJ, van den Wijngaard JP, Spaan JA, Siebes M. Coronary pressure-flow relations as basis for the understanding of coronary physiology. J Mol Cell Cardiol. 2012; 52: 786-793. [PubMed: 21840314]

31. van den Wijngaard JPHM, Schwarz JCV, van Horssen P, van Lier MGJTB, Dobbe JGG, Spaan JAE, Siebes M. 3D imaging of vascular networks for biophysical modeling of perfusion distribution within the heart. Journal of Biomechanics. 2013; 46:229-239. [PubMed: 23237670]

32. Vinnakota KC, Bassingthwaighte JB. Myocardial density and composition: a basis for calculating intracellular metabolite concentrations. Am J Physiol Heart Circ Physiol. 2004; 286:1742-1749.

33. Waller C, Kahler E, Hiller KH, Hu K, Nahrendorf M, Voll S, Haase A, Ertl G, Bauer WR. Myocardial perfusion and intracapillary blood volume in rats at rest and with coronary dilatation: MR imaging in vivo with use of a spin-labeling technique. Radiology. 2000; 215:189-197. [PubMed: 10751486] 
34. Wieringa PA, Spaan JAE, Stassen HG, Laird JD. Heterogeneous flow distribution in a three dimensional network simulation of the myocardial microcirculation - A hypothesis. Microcirculation. 1982; 2:195-216. 


\begin{tabular}{|c|c|c|c|}
\hline $\begin{array}{c}\text { Macroscopic } \\
\text { structural } \\
\text { identification }\end{array}$ & $\begin{array}{c}\text { Load 3D } \\
\text { microvascular } \\
\text { casting data }\end{array}$ & $\left\{\begin{array}{c}\text { Discretise } \\
\text { block into } \\
5 \times 5 \times 2 \text { sections }\end{array}\right.$ & $\begin{array}{c}\text { Perform } \\
\text { principal com- } \\
\text { ponent analysis }\end{array}$ \\
\hline $\begin{array}{c}\text { Vessel } \\
\text { classification }\end{array}$ & $\begin{array}{l}\text { Extract mean \& } \\
\text { S.D. of length } \\
\& \text { diameter } \\
\text { for each type }\end{array}$ & $\begin{array}{c}\text { Collect capil- } \\
\text { lary types in } \\
\text { transmural slices }\end{array}$ & $\begin{array}{c}\text { Group capillaries } \\
\text { into types } \\
C_{L}, C_{S}, C_{N} \\
\end{array}$ \\
\hline Homogenization & $\begin{array}{l}\text { Build synthetic } \\
\text { networks using } \\
\text { data statistics }\end{array}$ & $\begin{array}{l}\text { Solve capillary- } \\
\text { scale fluid } \\
\text { flow model }\end{array}$ & $\begin{array}{c}\text { Calculate } \\
\text { anisotropic } \\
\text { permeability }\end{array}$ \\
\hline
\end{tabular}

Figure 1.

Workflow diagram of the methods applied in this paper. 


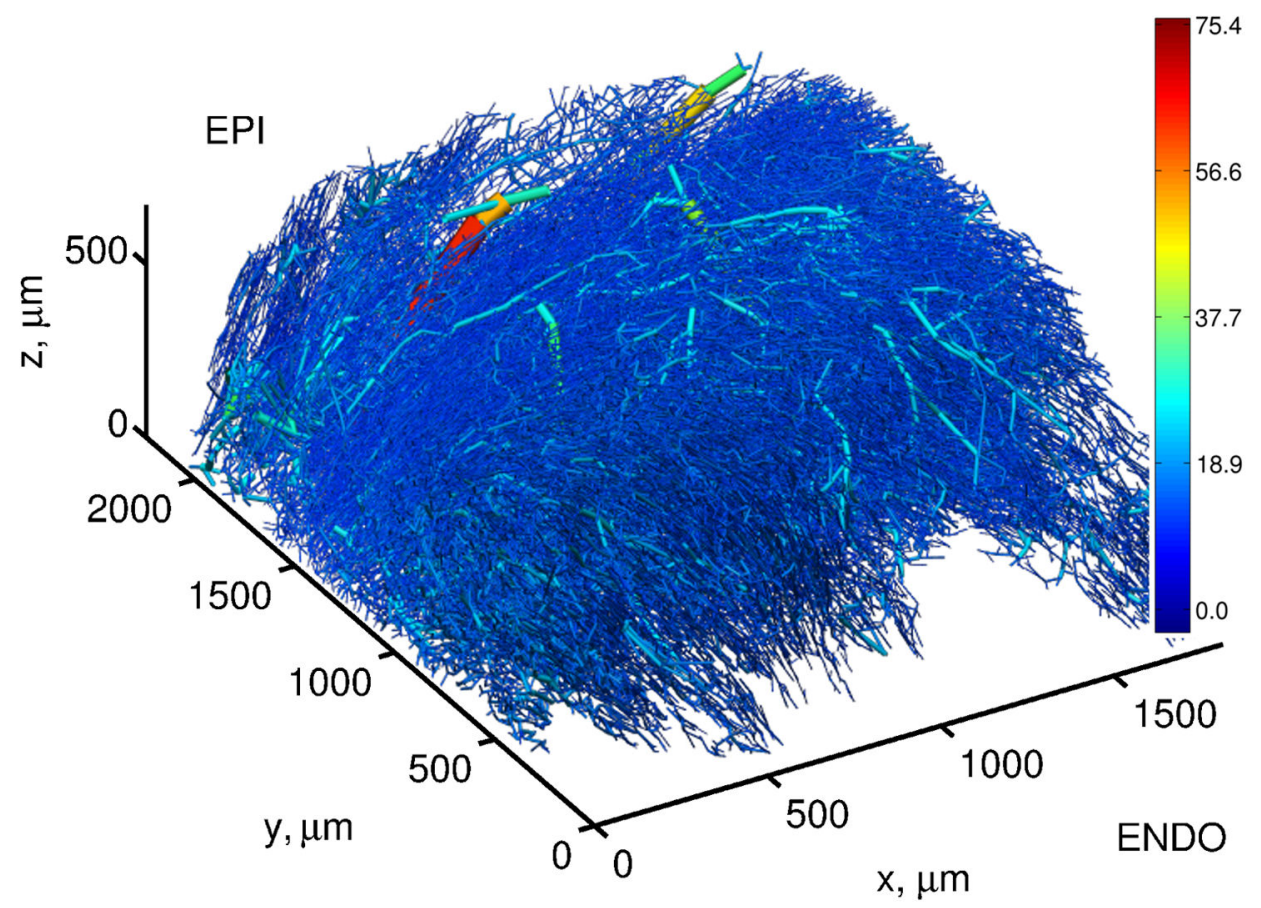

Figure 2.

The 3D rat coronary microvascular block of Lee et al. ${ }^{17}$, colored by diameter $(\mu \mathrm{m})$. This figure was produced using CMGUI, a 3D visualization software package available to download via http://www.cmiss.org/cmgui/. 


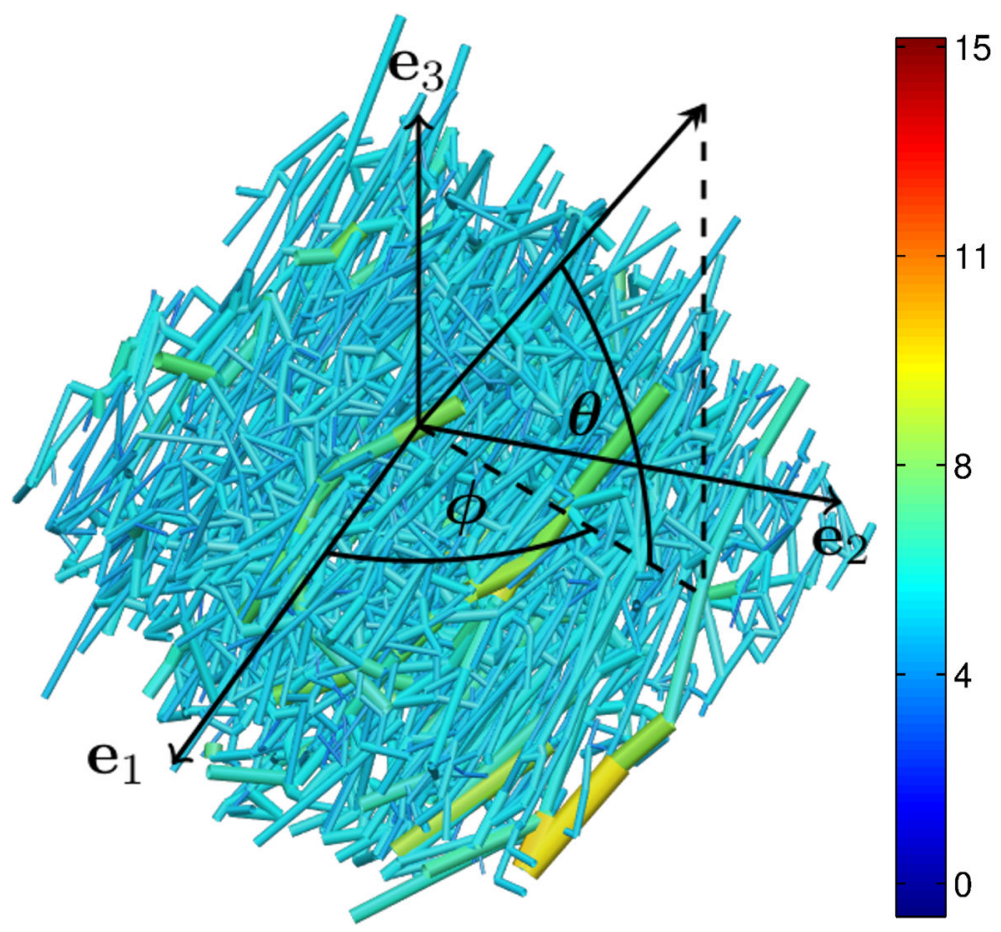

Figure 3.

Definition of spherical polar angles $\phi$ and $\theta$ with respect to the principal axes $\left\{\mathrm{e}_{1}, \mathrm{e}_{2}, \mathrm{e}_{3}\right\}$ for a sub-section of the microvascular block. Vessels are colored by diameter $(\mu \mathrm{m})$. 


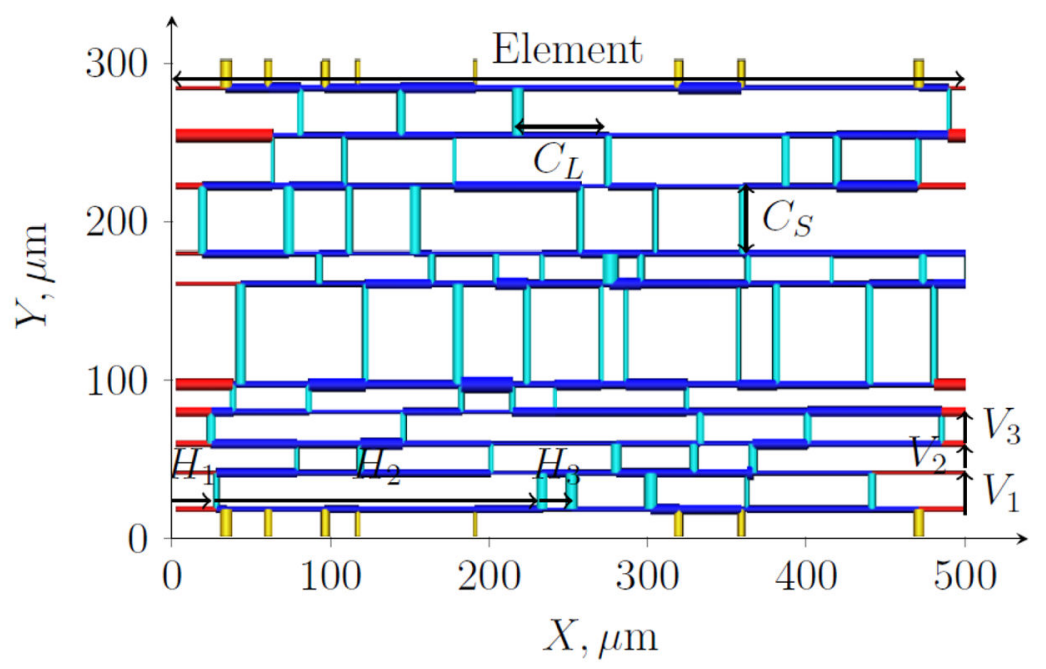

Figure 4.

Example of a stochastically-generated micro-cell network. Here, $V_{1}, V_{2}$ and $V_{3}$ indicate the first sampled vertical lengths (see Algorithm 1 in Supplementary Material) while $H_{1}, H_{2}$ and $H_{3}$ indicate the first three sampled horizontal lengths on the element at $Y=Y_{1}$. Crossconnections $C_{S}$ are shown in turquoise (in the interior of the micro-cell) or yellow (crossing the periodic boundary) while $C_{L}$ are colored dark blue (interior segments) or red (boundary segments). 

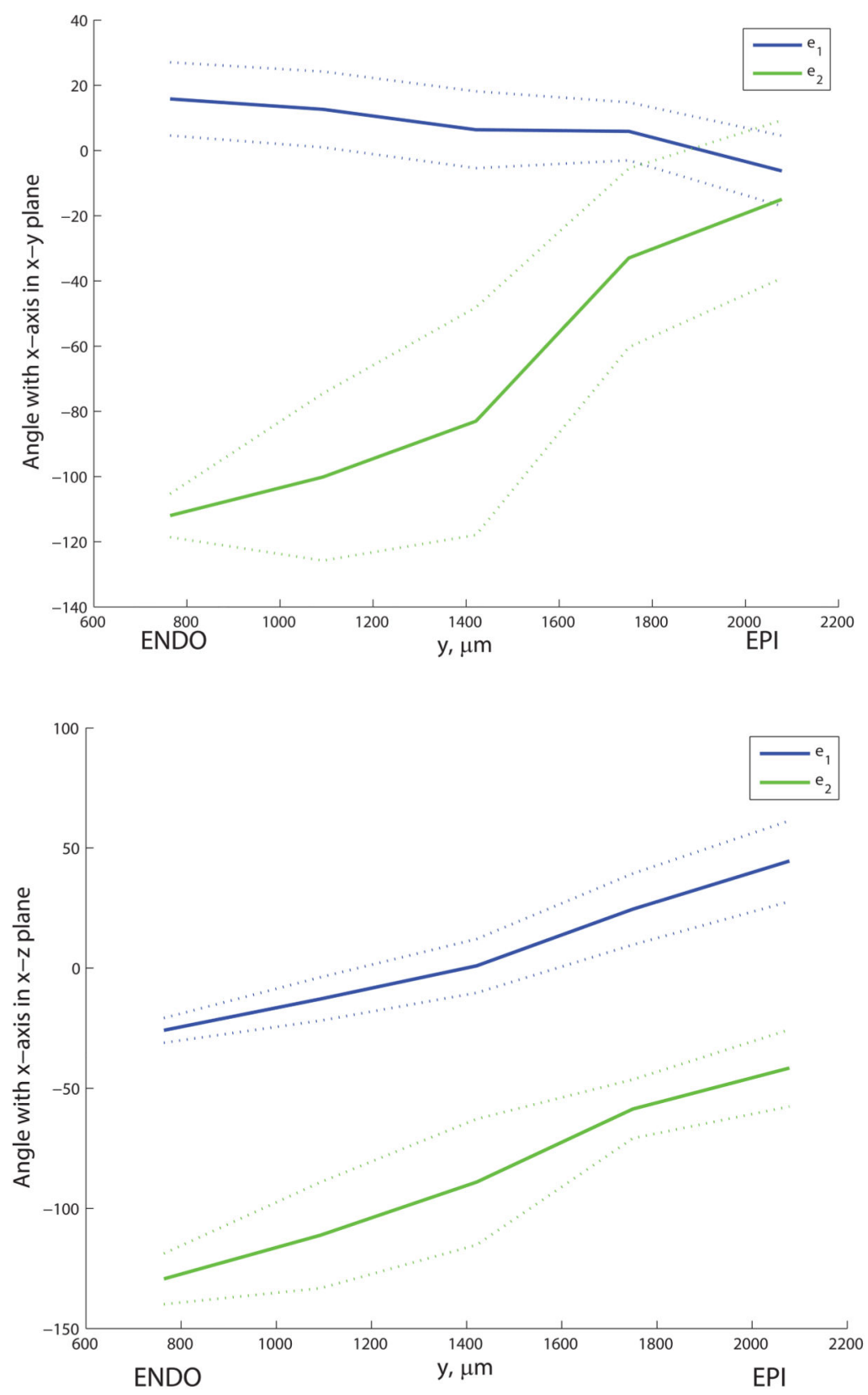

Figure 5.

Transmural variation in orientation of discretized principal axes $\mathbf{e}_{\mathbf{1}}$ and $\mathbf{e}_{2}$ for the microvascular block of Lee et al. ${ }^{17}$; mean (solid line) \pm S.D. (dotted lines) in the angles that each principal axis makes with the $\mathrm{x}$-axis when projected onto (a) the $\mathrm{x}-\mathrm{y}$ plane and (b) the $\mathrm{x}-\mathrm{z}$ plane. Values are averaged over $\mathrm{x}-$ and $\mathrm{z}$ - sections for each transmural slice. 


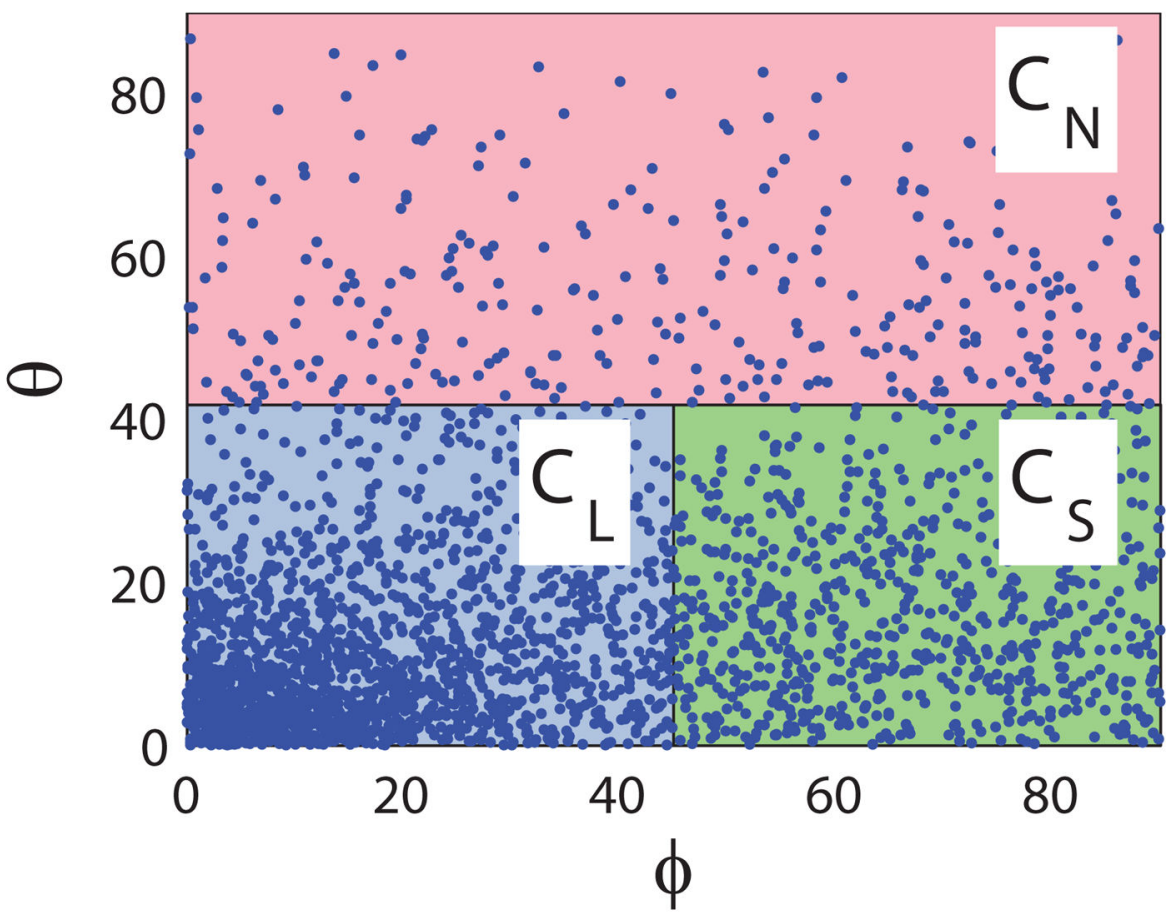

Figure 6.

A scatter plot of the (absolute values of) spherical polar angles $\phi$ and $\theta$ for each capillary relative to the principal axes. Capillaries are labelled as longitudinal $\left(C_{L}\right)$, in-sheet $\left(C_{S}\right)$ or sheet-normal $\left(C_{N}\right)$ according to their $\phi$ and $\theta$ values. 

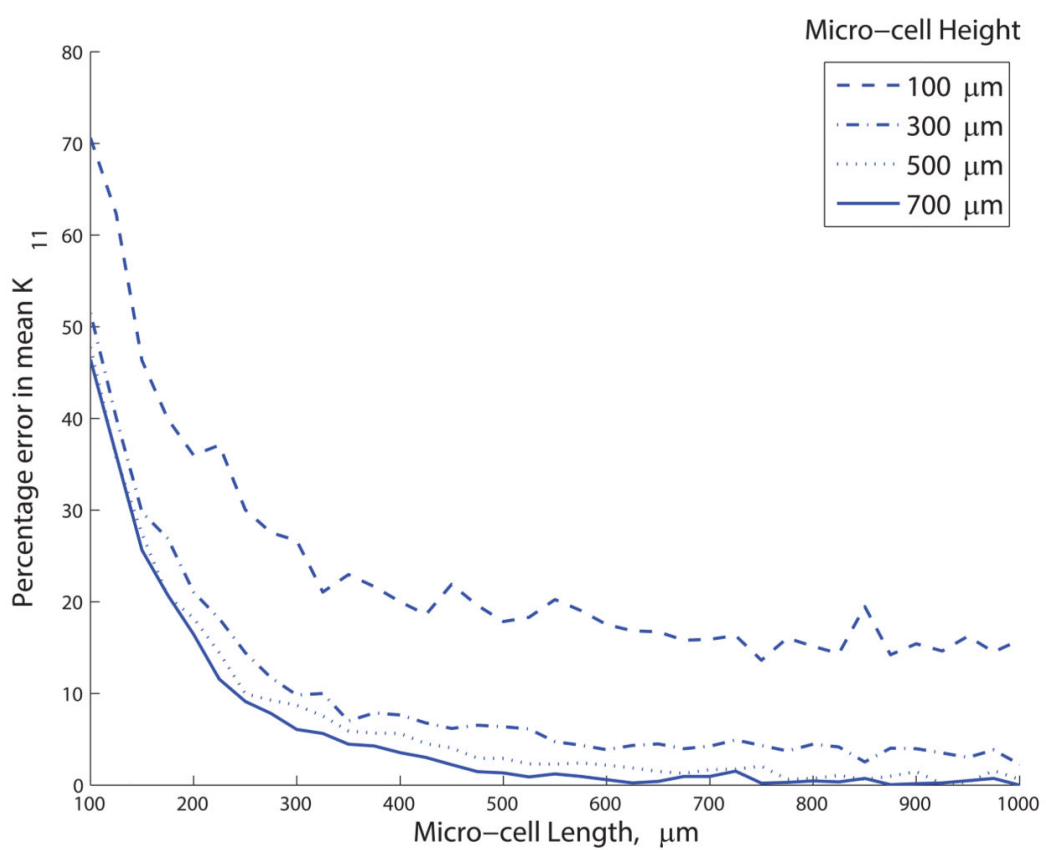

Figure 7.

Percentage error in mean $K_{11}$, relative to the mean $K_{11}$ for a micro-cell of dimensions 1000 $\times 700 \times 21.6 \mu \mathrm{m}^{3}$. Simulations in this study were performed for micro-cells of $500 \times 300 \times$ $21.6 \mu \mathrm{m}^{3}$, for which the percentage error was $6.4 \%$. 

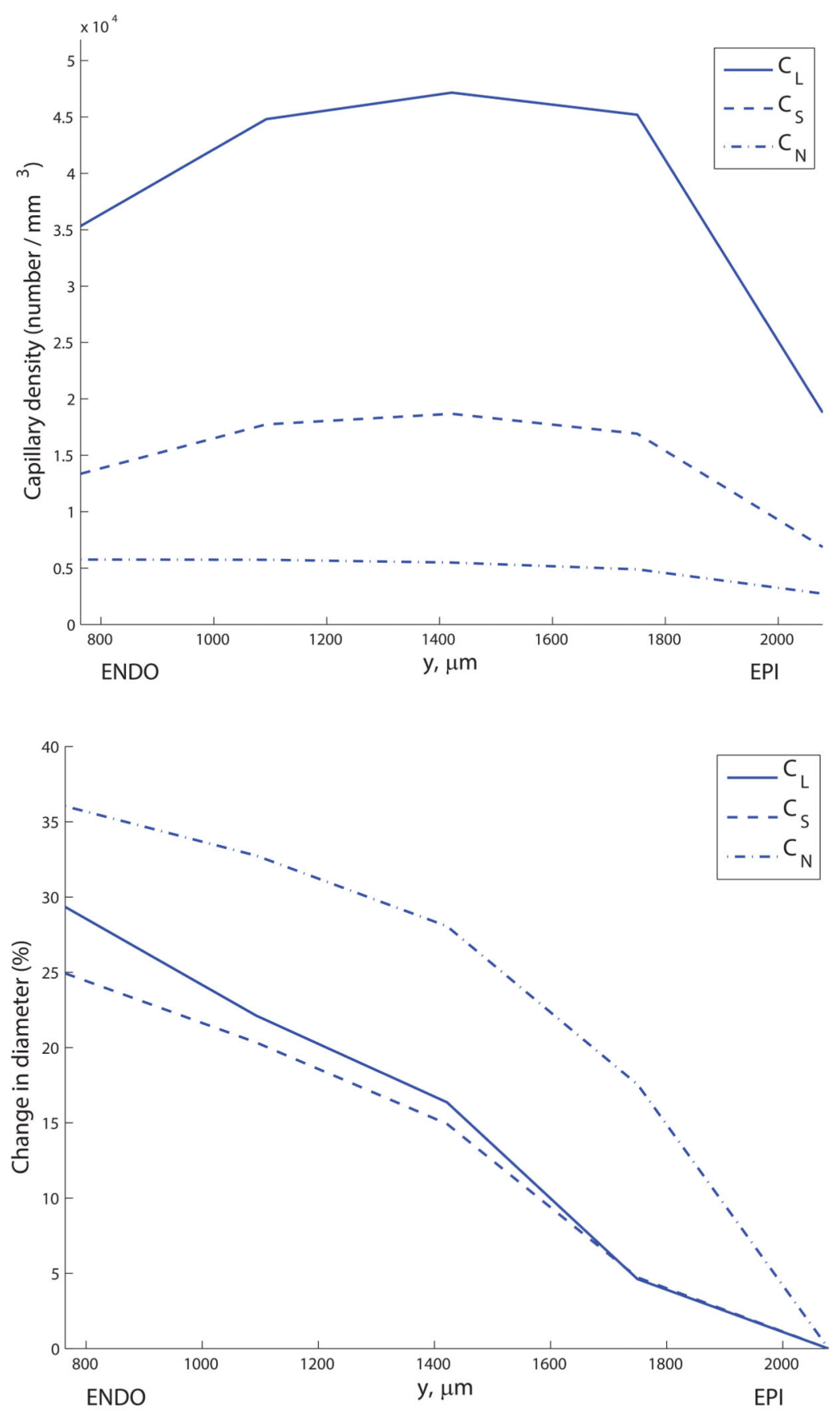


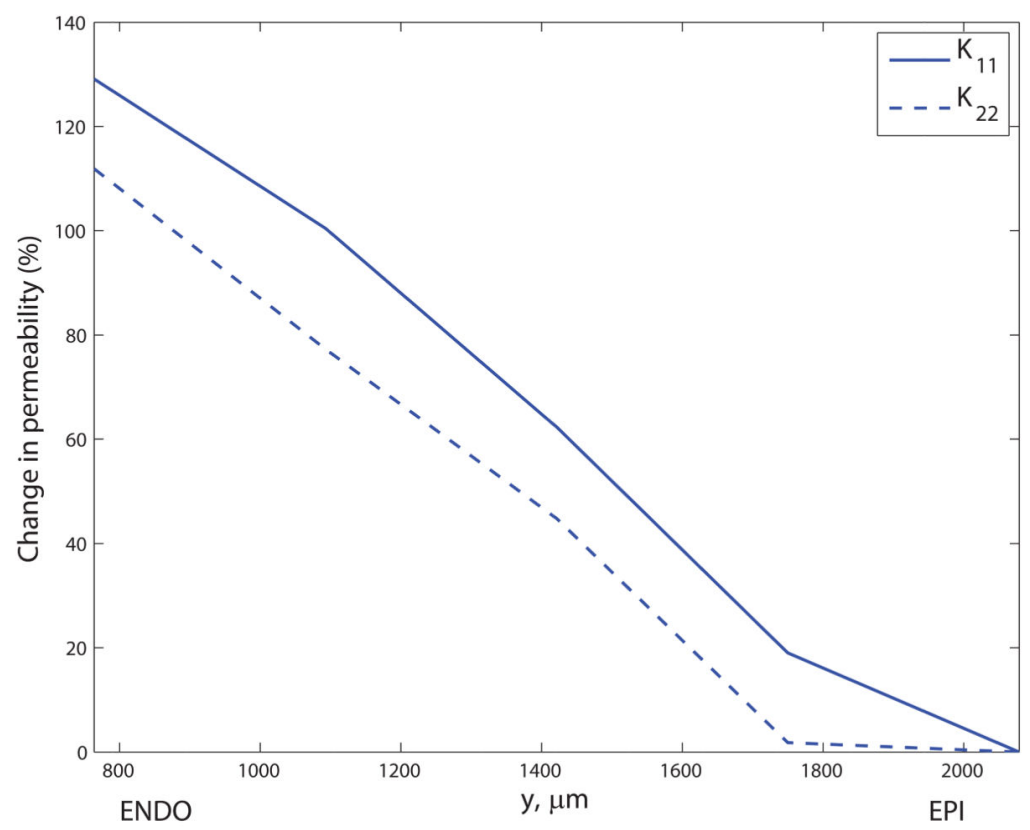

Figure 8.

Transmural variation in (a) capillary density (capillaries per $\mathrm{mm}^{3}$ ) for $C_{L}, C_{S}$ and $C_{N}$ segments; (b) mean diameter (percentage change relative to subepicardial values) for $C_{L}, C_{S}$ and $C_{N}$ segments; and (c) permeability components $K_{11}$ and $K_{22}$ (percentage change relative to subepicardial values). The $y$-coordinate corresponds to the mid-point of the discrete section of capillaries in the data set used to compute the principal axes. 


\section{Table 1}

Geometrical properties (mean \pm S.D.) of capillary types $C_{L}, C_{S}$ and $C_{N}$, collected over discrete sections of the microvascular block of Lee et al. ${ }^{17}$. Here, $\mathrm{N}$ is the number of capillaries, VF is the percentage of the total capillary volume occupied by each type, $\mathrm{L}$ is the length $(\mu \mathrm{m})$ and $\mathrm{D}$ is the diameter $(\mu \mathrm{m})$.

\begin{tabular}{|l|l|l|l|}
\hline & $C_{\boldsymbol{L}}$ & $\boldsymbol{C}_{\boldsymbol{S}}$ & $\boldsymbol{C}_{\boldsymbol{N}}$ \\
\hline $\mathrm{N}$ & 76508 & 29414 & 9839 \\
\hline $\mathrm{VF}$ & 71.6 & 21.8 & 6.6 \\
\hline $\mathrm{L}$ & $38.0 \pm 29.0$ & $24.9 \pm 15.7$ & $21.6 \pm 12.3$ \\
\hline $\mathrm{D}$ & $5.0 \pm 1.9$ & $5.2 \pm 1.9$ & $5.3 \pm 2.0$ \\
\hline
\end{tabular}


Table 2

Mean and S.D. of length and diameter of $C_{L}$ and $C_{S}$ segments, averaged over 1000 stochastically-generated micro-cell networks.

\begin{tabular}{|l|l|l|}
\hline Capillary Type & $\boldsymbol{C}_{\boldsymbol{L}}$ & $\boldsymbol{C}_{\boldsymbol{S}}$ \\
\hline Length $(\mu \mathrm{m})$ & $40.0 \pm 30.7$ & $23.7 \pm 14.9$ \\
\hline Diameter $(\mu \mathrm{m})$ & $5.0 \pm 4.2$ & $5.2 \pm 4.3$ \\
\hline
\end{tabular}




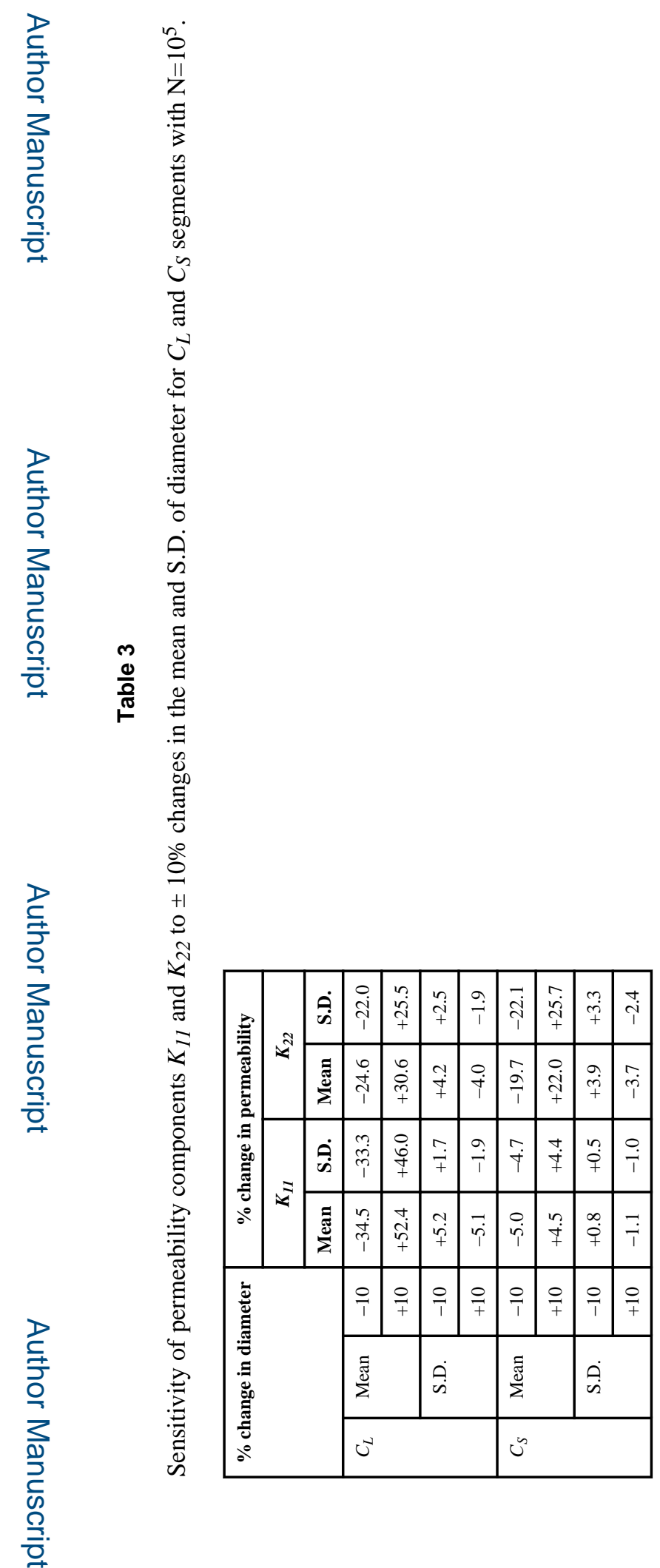

Ann Biomed Eng. Author manuscript; available in PMC 2015 September 01. 


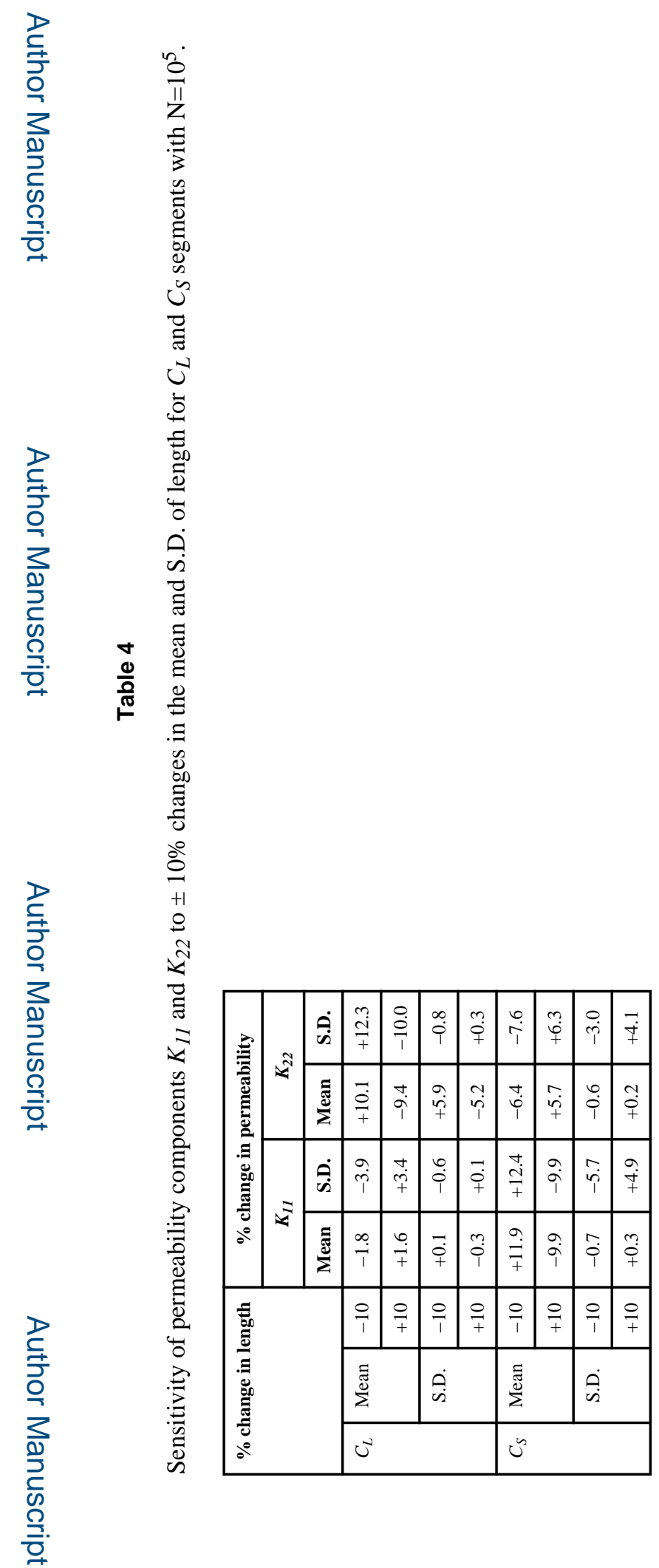

Ann Biomed Eng. Author manuscript; available in PMC 2015 September 01. 